\title{
THE EFFECT OF ELECTROSPUN FIBRE ALIGNMENT ON THE BEHAVIOUR OF RAT PERIODONTAL LIGAMENT CELLS
}

\author{
Shuhuan Shang ${ }^{1,2}$, Fang Yang ${ }^{2}$, Xiangrong Cheng ${ }^{1}$, X. Frank Walboomers ${ }^{2}$, and \\ John A. Jansen ${ }^{2 *}$
}

\begin{abstract}
${ }^{1}$ Key Lab for Oral Biomedical Engineering of Ministry of Education and Department of Periodontology, School and Hospital of Stomatology, Wuhan University, Wuhan, PR China

${ }^{2}$ Department of Biomaterials, Radboud University Nijmegen Medical Centre, P.O. Box 9101, 6500 HB Nijmegen,
\end{abstract} The Netherlands.

\begin{abstract}
It is envisioned that for the regeneration of highly organized structures, like tendon and ligaments, only aligned fibrous scaffolds can provide adequate topographic guidance to cells. In this study, a novel method to electrospin an aligned scaffold is presented. Electrospun fibres were deposited into a water bath and then the fibres were drawn to a rotating mandrel in a controlled manner. In this way, parallel and cross-aligned fibrous poly (lactide-co-glycolide) (PLGA) scaffolds were fabricated, which were subsequently used to study their effect on the growth behaviour of rat periodontal ligament (PDL) cells. First, the scaffolds were characterized regarding mechanical properties, scaffold stability and degradation in vitro. Then, rat PDL cells were seeded and cultured on these scaffolds for up to 7 days. Randomly oriented PLGA and solvent cast plain PLGA films served as controls. Results showed that the alignment of fibres resulted in a higher tensile stress and Young's modulus. Aligned scaffolds maintained their structural stability better compared to the controls after incubation in phosphate-buffered saline for 6 weeks. Further, cells were observed to elongate along the fibre after 3 days of culture. Proliferation and migration of PDL cells was significantly more prevalent on the aligned fibres compared to the controls. It was concluded that aligned scaffolds seem to be able to promote the organized regeneration of periodontal tissue.
\end{abstract}

Keywords: Poly(lactide-co-glycolide) (PLGA), electrospinning, periodontal tissue regeneration, alignment, periodontal ligament cells.

*Address for correspondence:

John A. Jansen

Department of Biomaterials

Radboud University Nijmegen Medical Centre

P.O. Box 9101

6500 HB Nijmegen, The Netherlands.

Telephone Number: +31243614920

FAX Number: +31243614657

E-mail: J.Jansen@dent.umcn.nl

\section{Introduction}

Periodontitis is a disease, which destroys the toothsupporting tissues, including the alveolar bone, periodontal ligament (PDL) and cementum, and forms a major cause of tooth loss in adults (Pihlstrom et al., 2005). Regeneration of the tooth-supporting tissues ideally must include the regrowth of the alveolar bone, PDL and cementum on the previously periodontitis-affected root surface. The PDL itself contains an organized structure of collagen fibres, which essentially attach a tooth to the alveolar bone. Current clinical periodontal therapy cannot promote the complete regeneration of periodontal tissues (Cortellini and Tonetti, 2000; Sanz and Giovannoli, 2000; Crea et al., 2008; Dori et al., 2008). Therefore, new approaches and materials are required to regenerate the lost periodontal tissues (Bartold et al., 2006; Edwards and Mason, 2006).

Already since the classical papers from Harrison (Harrison, 1912) and Weiss (Weiss, 1934), there has been interest in cell guidance along oriented structures. The research of Chew and co-workers (Chew et al., 2008) has shown that aligned electrospun scaffolds are beneficial for transplantation of 'primed' cells for enhancing peripheral nerve regeneration. Such an organized scaffold architecture provides topographic cues to adherent cells, resulting in an alignment of cells along the axes of the fibres (Lee et al., 2005; Zong et al., 2005; Chew et al., 2006). The ability to control cellular alignment on scaffolds can potentially be a powerful approach to recreate the micro- as well as nano-scale architecture of tissues. This can be important for the regeneration of a wide variety of human tissues with a specialized direction, like the periodontal ligament (Yin et al., 2010).

So far, aligned fibre structures can be obtained using the electrospinning technology (Yin et al., 2010; Yang et al., 2005; Xu et al., 2004). However, the current electrospinning setup only allows to collect aligned fibres with a limited scaffold thickness. With increasing thickness, the fibres become disordered as the residual charge accumulation on the deposited fibres interferes with the alignment of incoming fibres (Teo and Ramakrishna, 2006). Thin scaffolds are very difficult to use for tissue regeneration purposes due to their weak mechanical properties. Recently, we developed a new technique to overcome this drawback. Instead of using a metal collector, we deposit electrospun fibres on a liquid medium and then draw them to a rotating mandrel. In this way, controlled woven scaffolds composed of aligned fibre bundles can be obtained and the thickness of these 
scaffolds can be controlled by varying the electrospinning time.

In this study, we hypothesize that aligned scaffolds can improve the orientation, attachment, proliferation and migration of cells. Therefore, two types of aligned PLGA scaffolds were fabricated. The mechano-morphological properties, scaffold stability and biodegradation were evaluated. Subsequently, rat periodontal ligament (PDL) cells were cultured on the scaffolds up to 7 days, and compared to randomly oriented PLGA scaffolds (Random) and a solvent cast plain PLGA film (Control). The orientation, attachment, proliferation and migration changes of the rat PDL cells under the influence of the topographic cues from the electrospun fibres were evaluated.

\section{Materials and Methods}

\section{PLGA}

PLGA (50:50) was kindly provided by PURAC Biochem $\mathrm{BV}$ (Gorinchem, the Netherlands). It consisted of $52 \% \mathrm{D}, \mathrm{L}-$ lactide and $48 \%$ glycolide, with a molecular weight (Mw) of 153,000. Acetone, N,N-dimethylformamide (DMF), and Chloroform were all in HPLC grade and purchased from Lab-Scan Analytical Sciences (Gliwice, Poland) and VWR International (West Chester, PA, USA), respectively.

\section{Preparation of PLGA scaffolds}

To prepare aligned scaffolds, 20\% (w/v) PLGA solution was made by dissolving PLGA granules in acetone/DMF (60:40). Before electrospinning, the PLGA solution was fed into a glass syringe, which was controlled by a syringe pump (KD Scientific Inc., Holliston, MA, USA) at a feeding rate of $3.0 \mathrm{ml} / \mathrm{h}$. A Teflon tube was used to connect the syringe and a blunt-end nozzle with an inner diameter of $0.8 \mathrm{~mm}$, which was set up vertically. A grounded water bath was placed under the nozzle, and the distance between the water surface and nozzle was adjusted to $20 \mathrm{~cm}$. Next to the water bath, a motorized take-up mandrel of $7.8 \mathrm{~mm}$ in diameter was placed, of which the rotary and axial linear speed could be controlled separately (Fig. 1a). The rotary and axial linear speeds of the mandrel were set to $80 \mathrm{rpm}$ $\times 50 \mathrm{~mm} / \mathrm{min}$ or $80 \mathrm{rpm} \times 700 \mathrm{~mm} / \mathrm{min}$ to obtain Parallel and Cross aligned fibre structures. During electrospinning, a high voltage of $21 \mathrm{kV}$ was applied on the nozzle to generate a stable polymer jet. The resulting PLGA fibres were deposited on the water surface and then drawn by hand to the take-up mandrel. Thereafter, the drawing process was controlled by the take-up mandrel and the random fibres formed a fibre bundle wrapped around the mandrel.

To prepare the conventional electrospun scaffold with randomly oriented fibres (Random), 22\% (w/v) PLGA solution in acetone/DMF (60:40) was used. A rotating aluminium drum instead of the water bath was placed in the path of the polymer jet.

In order to fabricate the planar controls, PLGA films were prepared from $10 \%$ (w/v) PLGA chloroform solution by solvent casting.
All PLGA scaffolds were heat-treated at $70^{\circ} \mathrm{C}$ for 45 minutes to act as stress annealing for the fibres and to prevent intensive shrinking during cell culture. Then the scaffolds were freeze-dried for 3 days before further characterization and experimentation.

\section{Characterization of PLGA scaffolds}

The morphology of the fabricated scaffolds was observed by light microscopy (Leica MZ12 stereomicroscope, Leica Microsystems, Heerbrugg, Switzerland) and scanning electron microscopy (SEM) (JEOL 6310; JEOL, Tokyo, Japan). The average fibre diameter was assessed from 50 fibres in micrographs obtained at random locations. The average pores size on the surface of scaffolds was measured from the SEM micrographs as well. To examine the crosssections of the scaffolds, samples were frozen in OCT embedding matrix (CellPath, Newtown, UK), sectioned using a cryostat (Microm HM560, Thermo Scientific, Waltham, MA, USA) and observed under light microscopy (Imager Z1, Zeiss, Heidelberg, Germany).

\section{Fibre alignment and scaffold anisotropy as judged by Fast Fourier Transform}

Fast Fourier Transform (FFT) was used to characterize fibre alignment as a function of electrospinning conditions (Ayres et al., 2006). Briefly, digitized SEM micrographs were firstly converted to 8-bit greyscale TIF files, cropped to $1024 \times 1024$ pixels. Micrographs were processed with Image $\mathrm{J}$ software supported by an oval profile plug-in. A graphical depiction of the FFT frequency distribution was generated by placing a circular projection on the FFT output image and conducting a radial summation of the pixel intensities for each degree between $0^{\circ}$ and $180^{\circ}$, in $1^{\circ}$ increments. The amount of alignment present in the original data micrograph was reflected by the height and overall shape of the peak present in the FFT plot.

\section{Mechanical characterization}

Scaffolds were cut into $32 \times 5 \mathrm{~mm}^{2}$ rectangular shapes. The Parallel scaffolds were cut along the principal fibre axis. The Cross scaffolds were cut along the internal bisector between two principal fibre axes. The thickness of the scaffolds was measured with a calliper having a precision of $0.01 \mathrm{~mm}$. A Tensile test was conducted on a MTS 858 Mini BionixII test system (MTS Corp., Eden Prairie, MN, USA) equipped with a $250-\mathrm{N}$ load cell under a cross-head speed of $10 \mathrm{~mm} / \mathrm{min}$. Parallel scaffolds were mounted in the direction of the principal fibre axis. Cross scaffolds were mounted in the direction of the internal bisector between two principal fibre axes. The gauge length of samples was set at $20 \mathrm{~mm}$. Tensile stress was calculated based on the apparent cross-sectional area of the scaffolds. The Young's modulus of samples was calculated from the slope of the stress-strain curve in the linear region. Five samples were tested for each type of scaffold.

\section{Scaffold stability and biodegradation}

The scaffolds were cut into $10 \times 5 \mathrm{~mm}^{2}$ rectangular shapes and incubated in $1 \mathrm{ml}$ of phosphate-buffered saline (PBS) $(\mathrm{pH} 7.4)$ in $24-w e l l$ plates at $37^{\circ} \mathrm{C}$. The buffer solution 
a Electrospinning nozzle applied high voltage

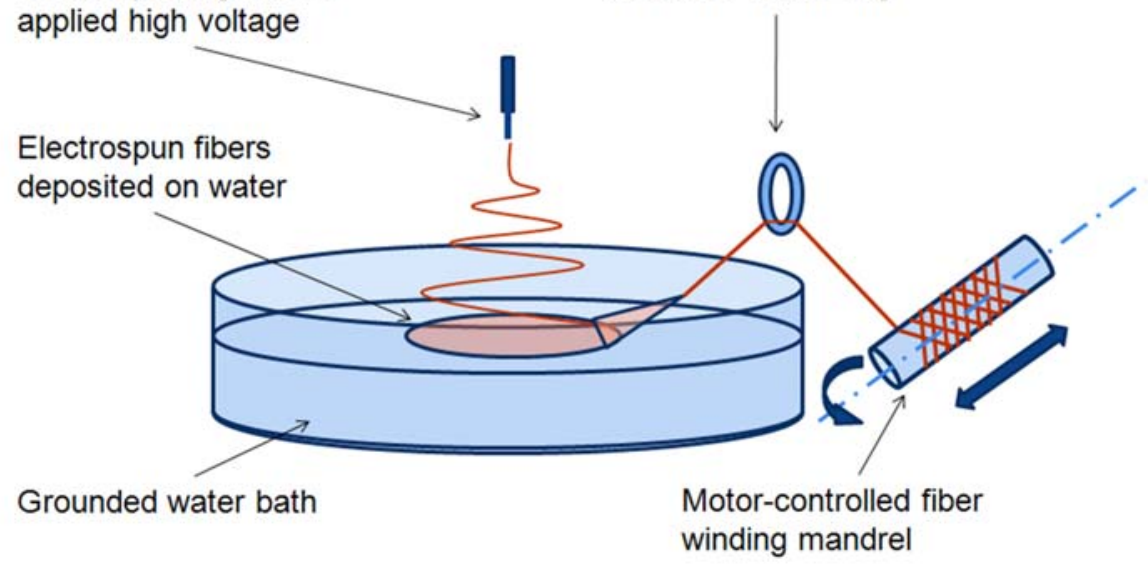

b

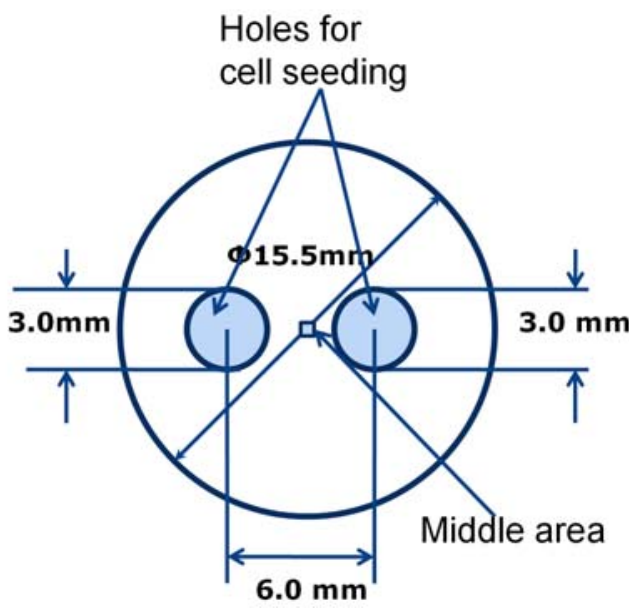

Fig. 1. Schematic diagrams of the set-up to collect aligned electrospun fibres (a) and the cell culture insert with two $3 \mathrm{~mm}$ circular areas for cell seeding (b).

was changed every 3-4 days to maintain the $\mathrm{pH}$ of the PBS constant.

At 1 hour and 1, 2, 3, 4, 5 and 6 weeks, scaffolds were taken out and freeze dried for 2 days. Subsequently, the dimensional shrinkage percentage and weight loss were determined according to the following formulae:

Shrinkage $(\%)=(1-$ Area after shrinkage/ Initial area $) \times 100$,

Mass loss $(\%)=(1-$ Mass after degradation/ Initial Mass $) \times 100$.

\section{Behaviour of PDL cells on scaffolds}

PDL cell culturing. PDL cells were derived from two extracted lower incisors of a Wistar rat with approval of the animal ethics committee of Radboud University Nijmegen Medical Centre (RU-DEC 2008-199). The culture procedure was done according to Mailhot et al. (Mailhot et al., 1995). Briefly, the mid-third portion of the root surfaces were collected carefully by scraping with a surgical scalpel and cultured in $\alpha$-MEM (Minimal Essential Medium) with $10 \%$ foetal calf serum (FCS), $60 \mu \mathrm{g} / \mathrm{ml}$ gentamycin and $0.25 \mu \mathrm{g} / \mathrm{ml}$ fungizone at $37^{\circ} \mathrm{C}$ in a humidified atmosphere of $95 \%$ air and $5 \% \mathrm{CO}_{2}$. Alkaline phosphatase (ALP) activity was assessed after 2-weeks of culturing to identify PDL cells. Cells of the 5th passage were used for the various assays as described below.

Cell seeding. For sterilization, all scaffolds were given a radio frequent glow discharge treatment (PDC-001, Harrick Scientific Corp., Pleasantville, NY, USA) in Argon plasma for $4 \mathrm{~min}$ followed by a rinse in $70 \%$ ethanol solution for $30 \mathrm{~min}$. After three washes in PBS, they were incubated in culture medium overnight before cell seeding.

Scaffolds with a size of $12 \times 12 \mathrm{~mm}^{2}$ were fixed in 24 well plate by a round cell culture insert with two holes of $3 \mathrm{~mm}$ inner diameter and positioned $3 \mathrm{~mm}$ apart (Fig. 1b). For the Parallel scaffolds, the connecting line of the two holes was in the same direction as the principal fibre axis. For the Cross scaffolds, the line was parallel to the internal bisector between two principal fibre axes. In either hole, $100 \mu \mathrm{l}$ PDL cell suspension, with a density of $4 \times 10^{5}$ cells $/ \mathrm{ml}\left(4 \times 10^{4}\right.$ per hole, or $\left.5.7 \times 10^{3} / \mathrm{mm}^{2}\right)$ was added to mimic the proliferation and migration of PDL cells into a defect area during periodontal tissue regeneration. At 5 hours of incubation, the inserts were removed and samples were rinsed with PBS to remove non-adherent cells. After that, $1 \mathrm{ml}$ of the above cell culture medium was added and changed every 2-3 days up to 7 days.

Cell morphology. Cell morphology was observed using SEM at hour 5, day 3 and 7. The cell-scaffold samples were fixed in $2 \%(\mathrm{v} / \mathrm{v})$ glutaraldehyde in $0.1 \mathrm{M}$ sodium-cacodylate buffered solution for $5 \mathrm{~min}$, rinsed in cacodylate buffered solution, dehydrated with increasing concentrations of ethanol, and finally air dried in tetramethylsilane (TMS, Merck, Darmstadt, Germany) overnight. After drying, the specimens were sputter-coated with gold. This experiment was done in duplicate at all time-points.

Cytoskeletal orientation was observed using confocal laser scan microscopy (CLSM, Olympus FV1000) for samples cultured for 5 hours, 3,5 and 7 days. Fixation of the cell-scaffold samples was carried out for 15 minutes 


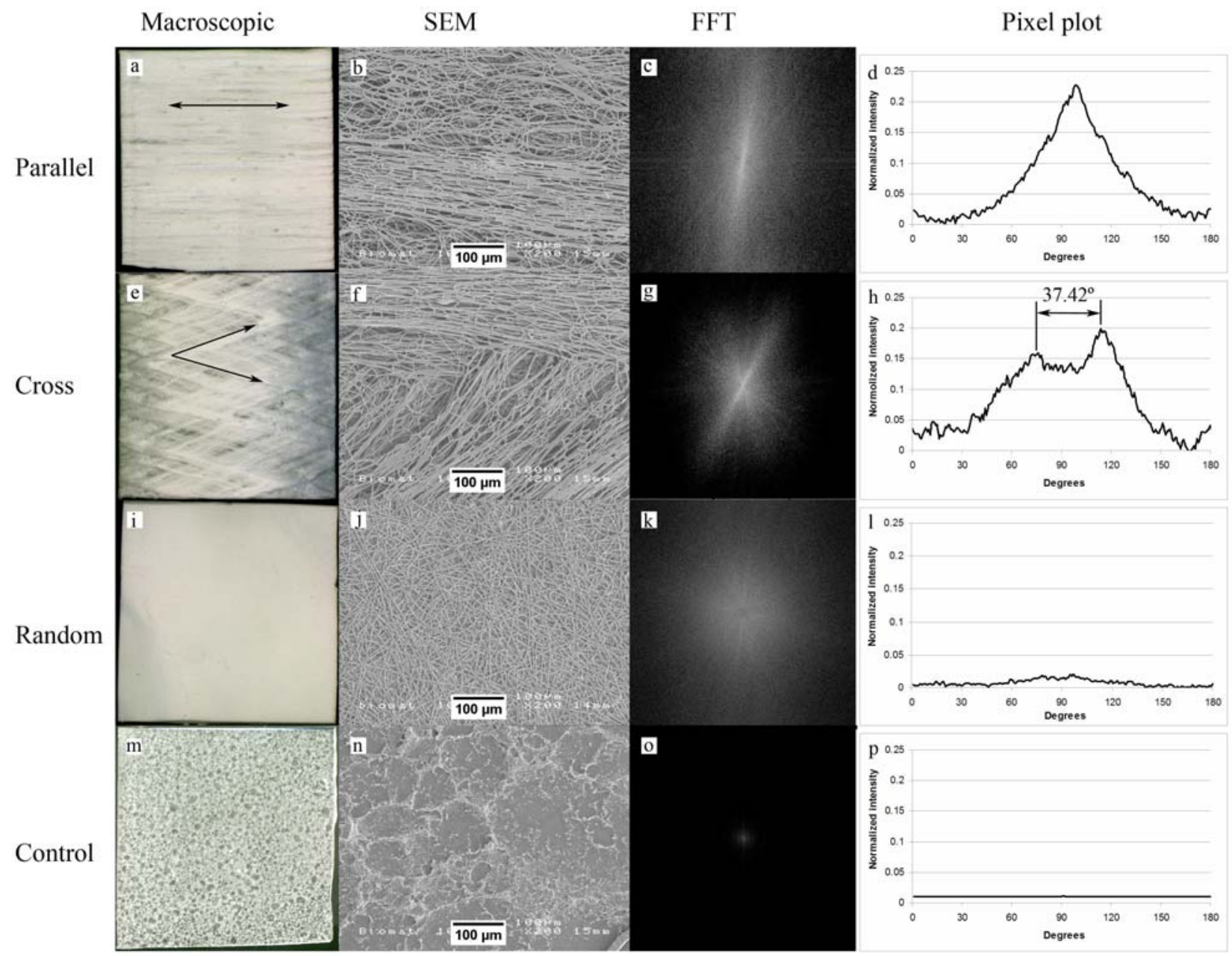

Fig. 2. Macroscopic appearance, SEM micrographs, FFT output images, and pixel intensity plots against the angle of acquisition of Parallel (a-d), Cross (e-h), Random (i-l) and Control (m-p). The FFT data for the aligned fibres (b and f) resulted in an output image containing pixels in one specific orientation distribution (c and $\mathbf{g})$. In contrast, the FFT data for random fibres (j) generated an output image containing pixels distributed in a symmetrical, circular shape (k). The FFT of a data SEM image of PLGA films without fibres (n) did not generated an output image containing pixels $(\mathrm{O})$. Note the distinctive peaks produced by the micrographs containing aligned fibres (d and $\mathbf{h})$.

in freshly prepared $2 \%(\mathrm{w} / \mathrm{v})$ paraformaldehyde and $0.2 \%$ $(\mathrm{v} / \mathrm{v})$ glutaraldehyde. Then the samples were washed in PBS three times, permeabilized in PBS containing a $1 \%$ (v/v) Triton-X 100 (Sigma Aldrich, St. Louis, MO, USA) for $15 \mathrm{~min}$, incubated in PBS containing a $5 \%(\mathrm{w} / \mathrm{v})$ bovine serum albumin (BSA) (Sigma) and 0.1\% (v/v) Tween 20 (Merck-Schuchardt, Hohenbrunn, Germany) for 30 min. Thereafter, they were stained with 1:250 Phalloidin-Alexa 568 and 1:2500 DAPI (Invitrogen, Carlsbad, CA, USA) for 2 hours, and thoroughly washed with PBS. Finally, the specimens were rinsed with deionised water for $1 \mathrm{~min}$ and mounted in VECTASHIELD ${ }^{\circledR}$ Mounting Medium (Vector Laboratories, Inc., Burlingame, CA, USA) on glass slides. Specimens were visualized and photographed using Olympus FV1000 confocal laser scanning microscopy (Olympus, Tokyo, Japan) with excitation wavelengths of $488 \mathrm{~nm}$ and $642 \mathrm{~nm}$ and emission wavelengths of $525 \mathrm{~nm}$ and $661 \mathrm{~nm}$ for Phalloidin-Alexa 568 and DAPI, respectively. This experiment was done in triplicate at all different time points.

Cell attachment, proliferation and migration. Three specimens of each scaffold were assessed at 5 hours, 3, 5 and 7 days of incubation. Quantification of the metabolism of PDL cells was carried out using an Alamar Blue (AB) detection kit (Invitrogen). In brief, $1 \mathrm{ml} \mathrm{10 \%} \mathrm{(v/v)} \mathrm{AB}$ solution was directly added to the culture medium in each well. The plate was further incubated at $37^{\circ} \mathrm{C}$ for 4 hours. Measurement of each sample at 530 (excitation) and $590 \mathrm{~nm}$ (emission) was performed with a fluorescence microplate reader (Bio-Tek instruments Inc., Winooski, VT, USA). The absorbance was corrected using the value of $10 \%(\mathrm{v} / \mathrm{v}) \mathrm{AB}$ solution in medium without cells as negative control. The scaffolds without cells were also used as negative control in the $\mathrm{AB}$ assay giving the same absorbance as $\mathrm{AB}$ solution in medium, indicating no interaction between $\mathrm{AB}$ and the scaffolds.

Quantification of total DNA content was carried out using a PicoGreen DNA detection kit (Molecular Probes, Leiden, The Netherlands). After washing in PBS, each scaffold was transferred to a clean tube and $1 \mathrm{ml}$ deionised water was added to lyse the cells. Thereafter, the cellscaffold samples were frozen and thawed twice. Then, 100 $\mu \mathrm{l}$ of PicoGreen working solution was added to $100 \mu \mathrm{l}$ supernatants of the samples. Subsequent to 2-5 min of incubation, the DNA was measured using a fluorescence microplate reader (Bio-Tek instruments) with an excitation 

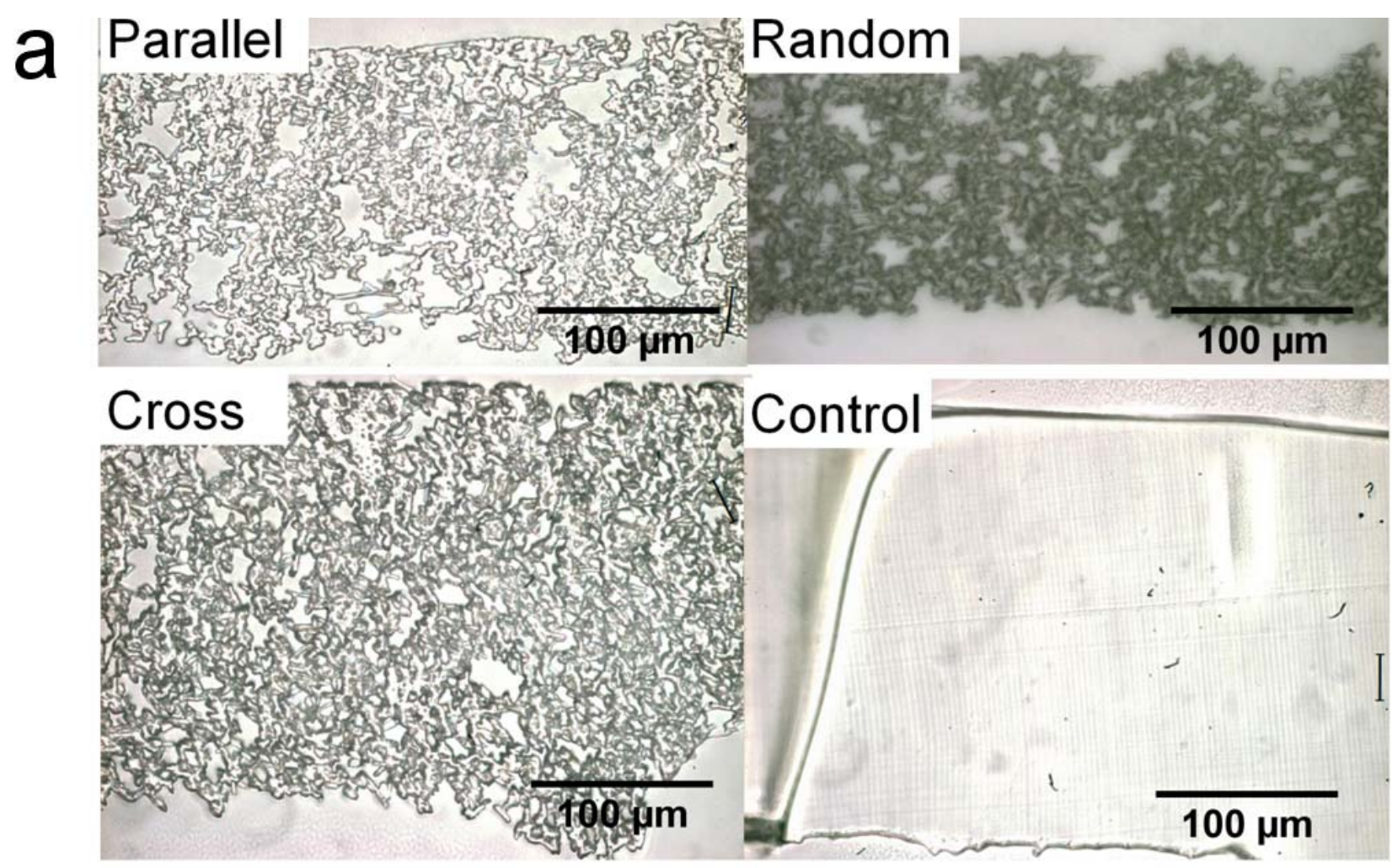

b

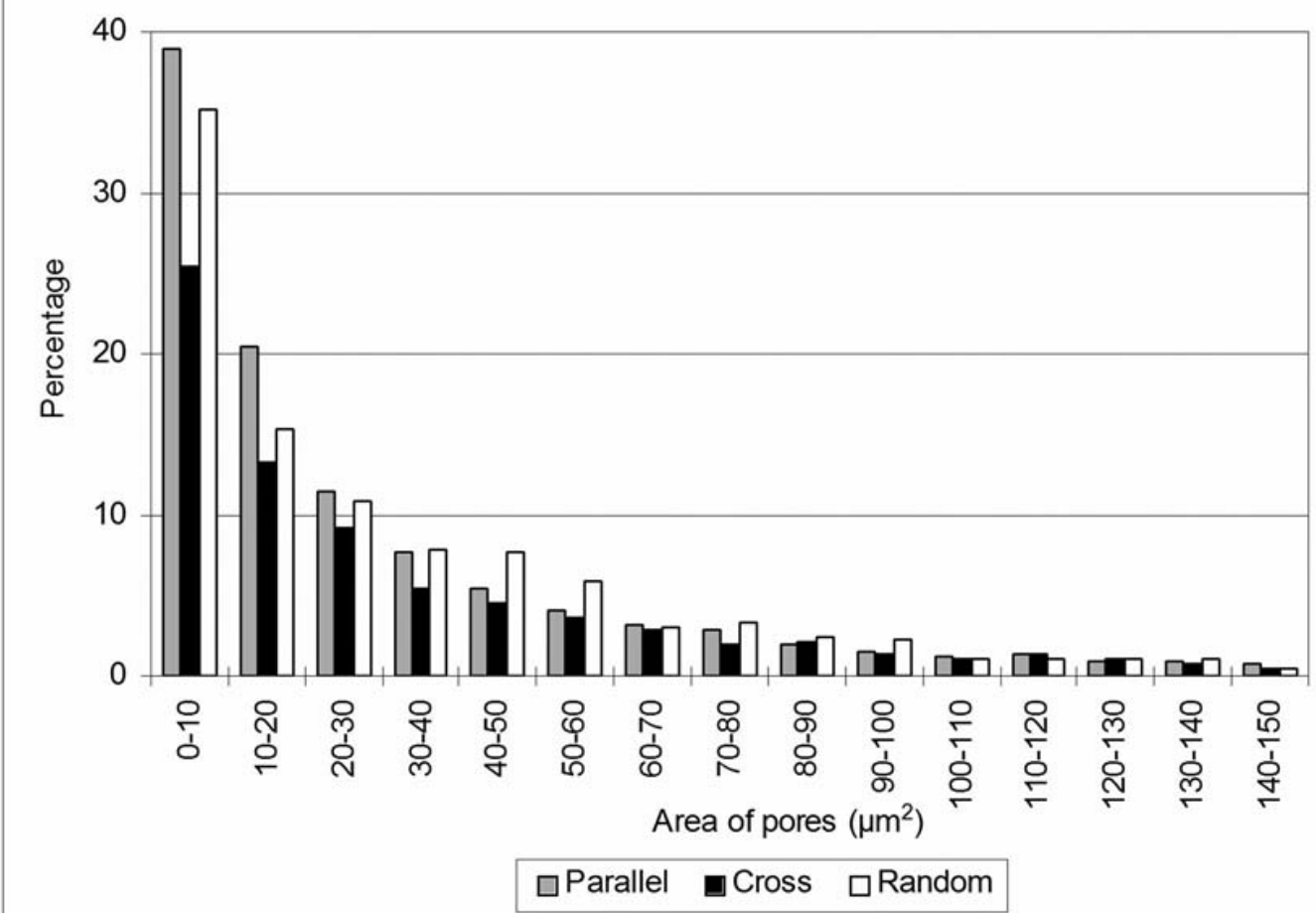

Fig. 3. The light microscopy images of the cross-sections (a) and the pore size distribution (b) of the different scaffolds.

of $265 \mathrm{~nm}$ and an emission of $450 \mathrm{~nm}$. The DNA amounts were calculated in relation to a standard curve.

Surface coverage in the middle area of the scaffolds was counted to evaluate the ability of scaffolds to guide the repopulation of PDL cells into the defect space (Fig. 1b). The samples were assessed on a $681.94 \times 510.93 \mu \mathrm{m}$ middle area with the use of automated Zeiss fluorescence microscopy (Imager Z1). Using a Leica ${ }^{\circledR}$ Qwin Pro-image analysis system (Wetzlar, Germany), the number of cell nuclei (DAPI staining, blue) on the middle area of the scaffolds was calculated.

\section{Statistical analysis}

All results were expressed as means \pm standard deviations. The data were analyzed using one-way analysis of variance (ANOVA), followed by Tukey-Kramer Multiple Comparisons Test. 


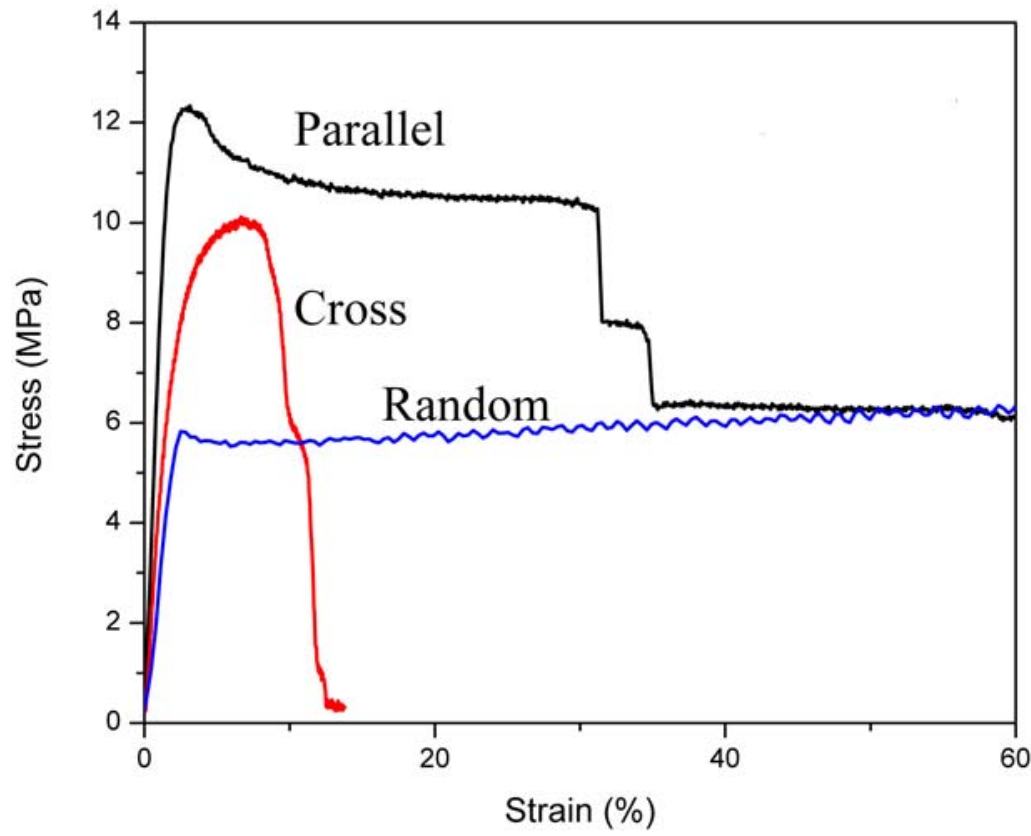

Fig. 4. The typical tensile stress-strain curves of the different scaffolds.
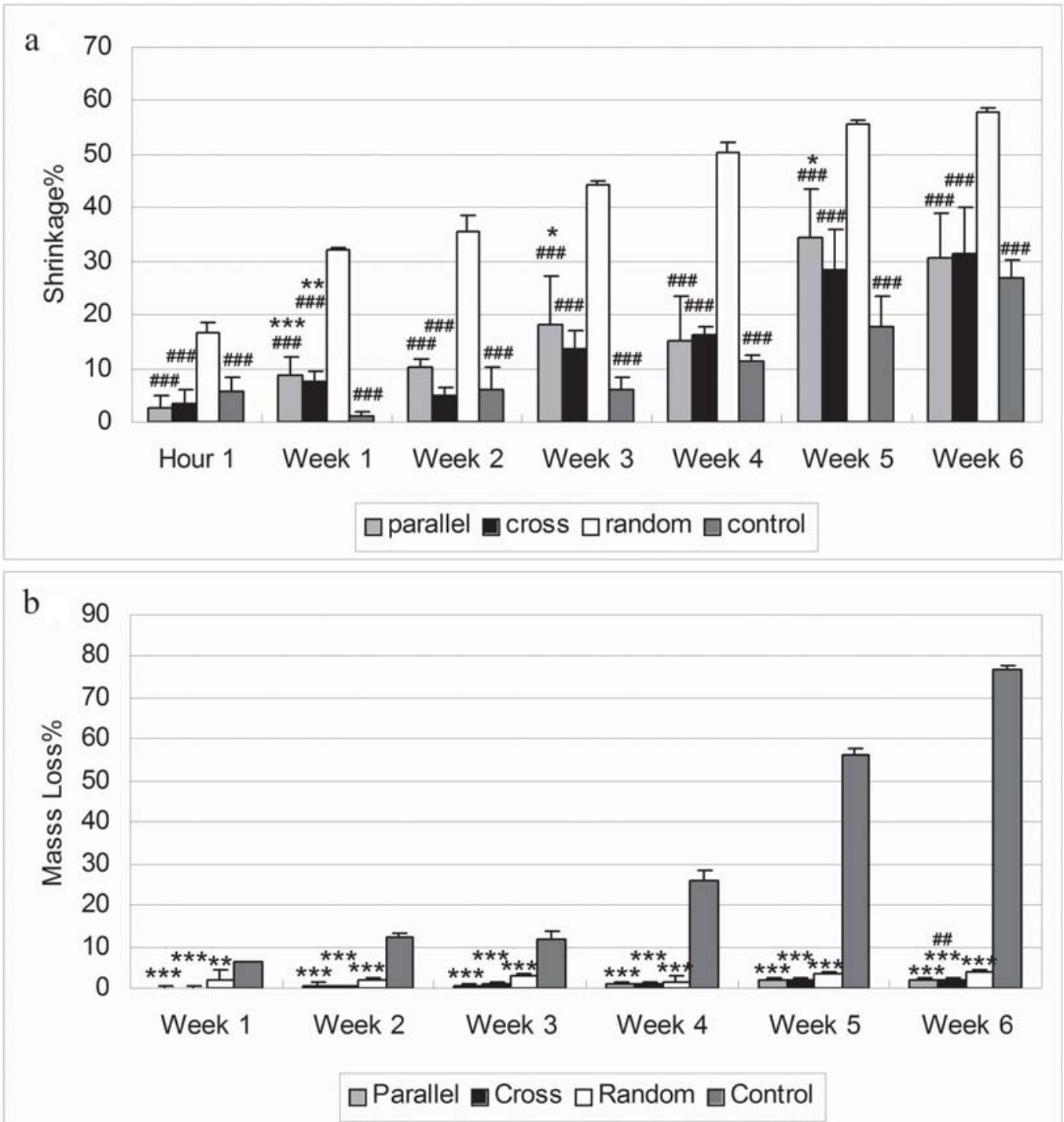

Fig. 5. The percentage of shrinkage (a) and degradation in vitro on mass loss (b) of PLGA scaffolds during 6 weeks.

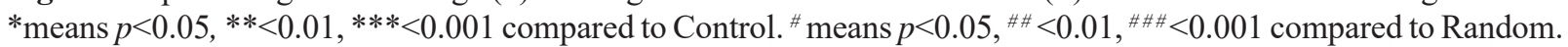




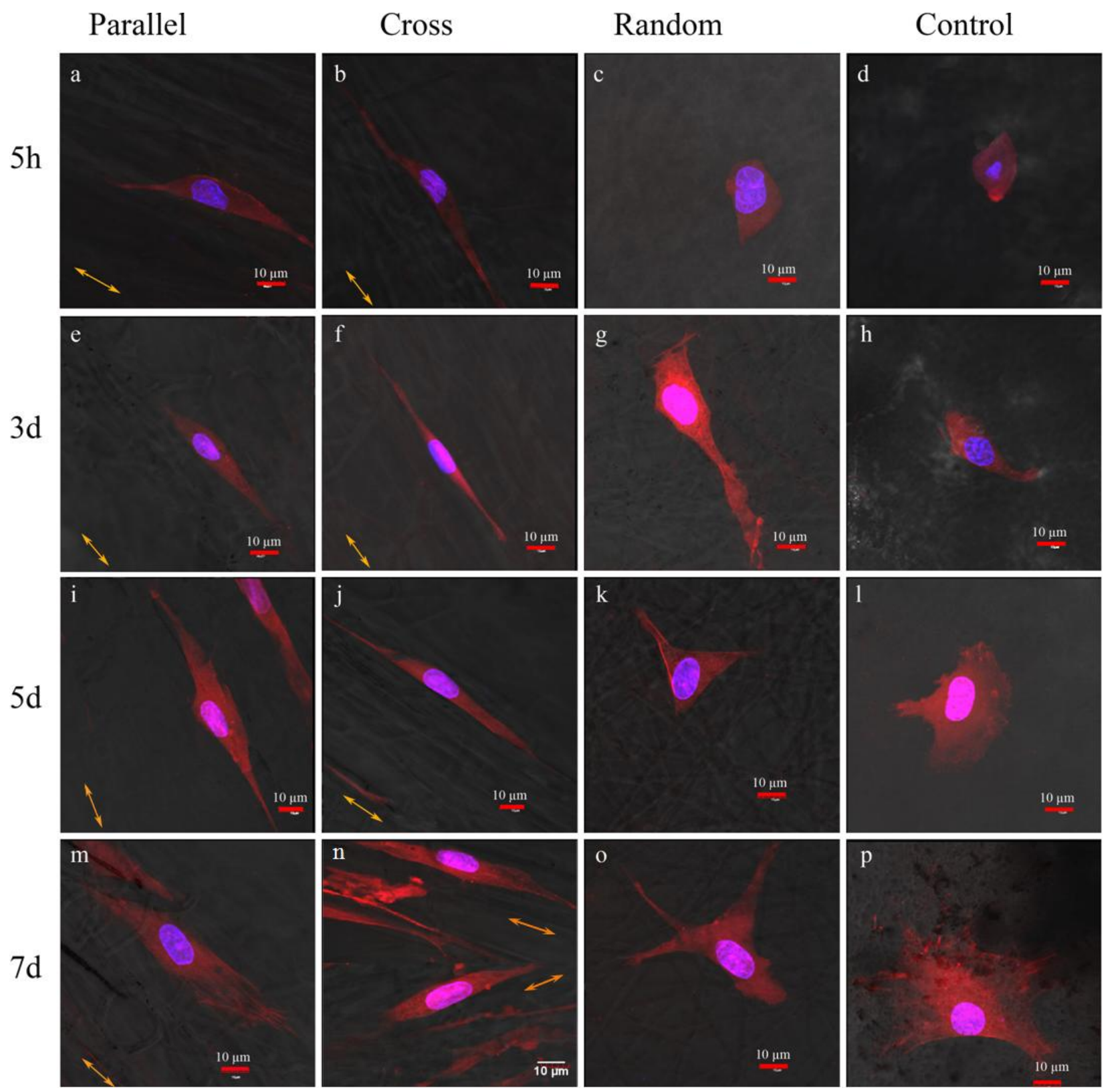

Fig. 6. Confocal fluorescent micrographs of PDL cells cultured on PLGA scaffolds at 5 hours (a-d), day 3 (e-h), 5 (i-l) and 7 (m-p). Parallel (a, e, i and $\mathbf{m})$, Cross (b, f, j and $\mathbf{n})$, Random (c, g, k and $\mathbf{o})$, and Control (d, h, $\mathbf{l}$ and $\mathbf{p}$ ). Arrows in $(\mathbf{a}, \mathbf{b}, \mathbf{e}, \mathbf{f}, \mathbf{i}, \mathbf{j}, \mathbf{m}$ and $\mathbf{n})$ indicate the direction of the principal axis of the aligned fibres. At 5 hours, PDL cells attached and spread out with different shape on scaffolds ( $\mathbf{a}$ and $\mathbf{b})$. After 3 days of culture, cells on Parallel and Cross aligned and elongated along the principal axis of fibres in a spindle shape $(\mathbf{e}, \mathbf{f}, \mathbf{i}, \mathbf{j}, \mathbf{m} ; \mathbf{n}$ is a merged figure from one sample indicating both cellular directions as found in the cross samples). On Random, cell orientation was in a polygonal shape with stretching the cell cytoskeleton across multiple fibres ( $\mathrm{g}$, $\mathrm{k}$ and o). On Control, cells spread out without any orientation (h, $\mathbf{l}$ and $\mathbf{p})$. Red: actin cytoskeleton, blue: DAPI.

\section{Results}

\section{Properties of PLGA scaffolds}

Scaffold structure. On the macroscopic scale, the aligned electrospun scaffolds had an uneven fibrous morphology with a porous structure. The principal axis of the fibres in the Parallel specimens was oriented in a single direction. The majority of fibres in the Cross scaffolds were aligned in two directions. Random and Control scaffolds showed no fibrous morphology and porous structure. Random scaffolds had an even and smooth surface. The solvent cast plain film was translucent and presented wave-like features (Fig. 2). All four types of scaffolds were approximately $200 \mu \mathrm{m}$ in thickness. The cross-sections of different scaffolds are presented in Fig. 3a.

In the SEM micrographs, the average fibre diameters of the Parallel, Cross and Random scaffolds were not significantly different, i.e., $2.15 \pm 0.55,2.18 \pm 0.60$ and $2.14 \pm 0.68 \mu \mathrm{m}$, respectively $(p>0.05)$. The average pore sizes of the surface of Parallel, Cross and Random scaffolds were also similar, i.e., $38.06 \pm 60.30,41.70 \pm 22.92$, and $37.53 \pm 48.67 \mu \mathrm{m}^{2}$, respectively $(p>0.05)$. The pore size distribution is shown in Fig. 3 b.

Fibre alignment and scaffold anisotropy as judged by FFT. The peak height in the FFT plot increased when the fibres were more aligned along a single axis of 

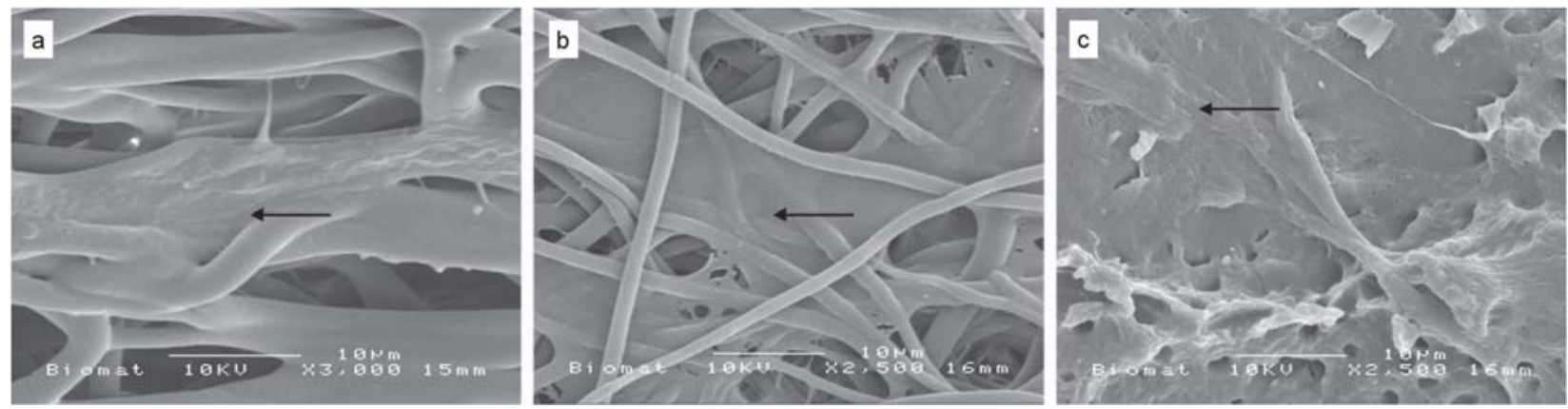

Fig. 7. Representative SEM micrographs of cells growing on aligned scaffolds (a), Random (b) and Control (c) after 7 days. Cells on the aligned electrospun fibres grew elongated along the fibre axis in a spindle shape. Cells on Random grew in a polygonal shape according to the multiple directions of the different fibres. On Control, cells spread out without a preferential orientation. Arrows indicate the cells on fibres.
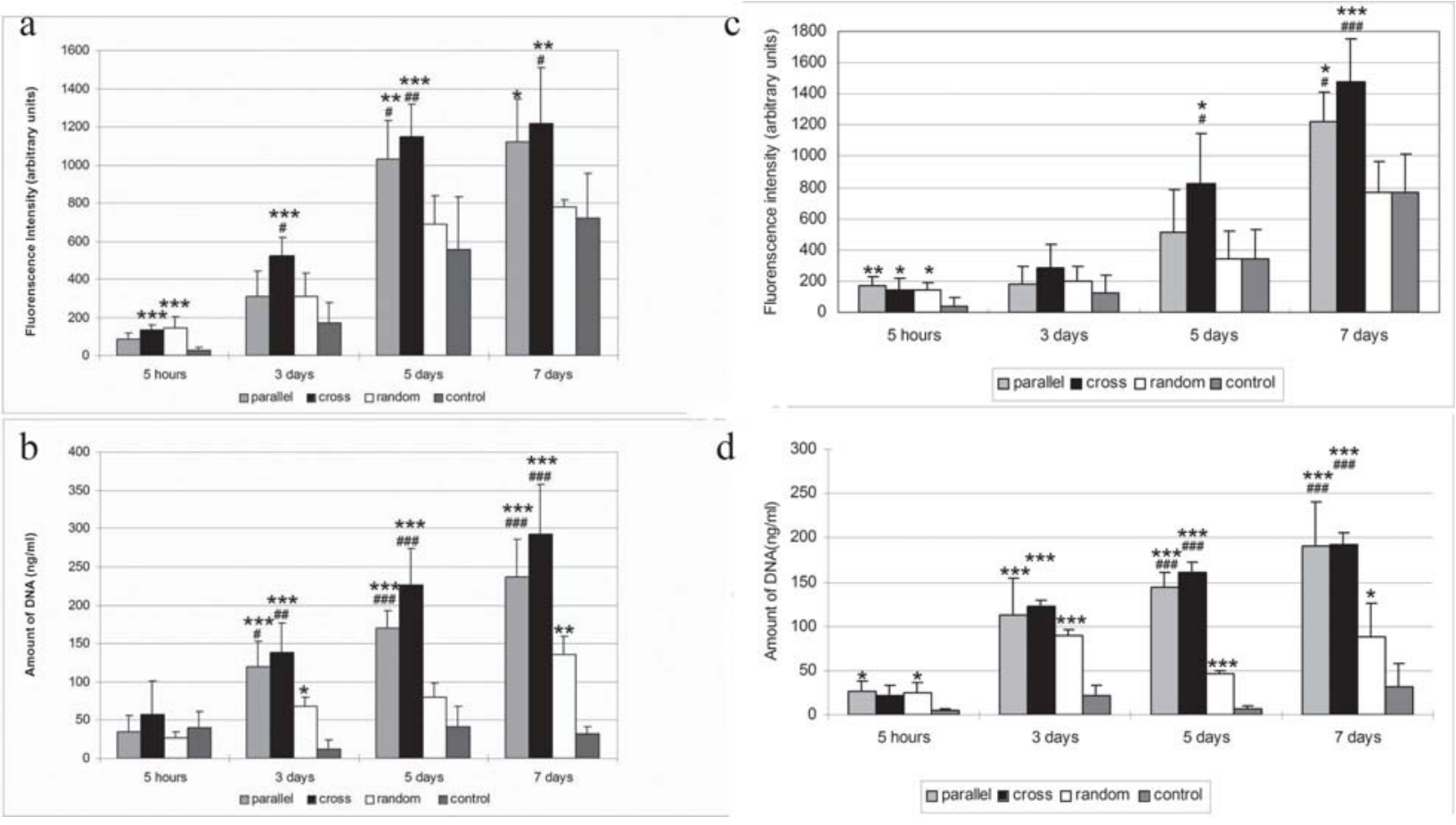

Fig. 8. Quantification of metabolism tested by Alamar Blue assay (a and $\mathbf{c}$ ) and DNA amount tested by PicoGreen assay ( $\mathbf{b}$ and $\mathbf{d}$ ) of rat PDL cells on different kinds of scaffolds at hour 5, day 3, 5 and 7. Figure $\mathbf{a}$ and $\mathbf{b}$ are from the first run, figure $\mathbf{c}$ and $\mathbf{d}$ from the second run. Bars represent standard deviation (SD). * means $p<0.05$, **<0.01, $* * *<0.001$ compared to Control; ${ }^{\#}$ means $p<0.05$, ${ }^{\#}<0.01$, ${ }^{\# \# \#}<0.001$ compared to Random.

orientation (Fig. 2). The normalized intensity values (or FFT alignment value) of Parallel scaffolds with a single peak was the highest $(0.23)$. There were two peaks at 0.16 and 0.19 arbitrary units for Cross scaffolds, at a distance of $37.42^{\circ}$. In contrast, Random scaffolds did not show overt evidence of alignment.

Mechanical characterization of electrospun PLGA scaffolds. Fig. 4 shows the typical tensile stress-strain curves of the different scaffolds. The alignment of fibres of electrospun PLGA scaffolds resulted in a higher tensile stress and Young's modulus. The tensile stress of the Parallel scaffolds was the highest with a Young's modulus of $775 \pm 35 \mathrm{MPa}$, followed by the Cross $(446 \pm 50 \mathrm{MPa})$ and Random $(209 \pm 71 \mathrm{MPa})(p<0.001)$ scaffolds. It has to be noted that the tensile force was applied along the principal fibre axis of the Parallel scaffolds, as this type of scaffold was easily torn when the tensile force was applied in a perpendicular direction to the fibres.

Scaffolds stability and biodegradation. The percentage of shrinkage and degradation in vitro is shown in Fig. 5a and b. All scaffolds showed shrinkage over time. Strikingly, Random scaffolds revealed significantly more shrinkage at all time points compared to Control scaffolds and both types of aligned scaffolds. The percentage of shrinkage was similar for Parallel and Cross aligned scaffolds $(p>0.05)$.

All scaffold types degraded to some extent over time (Fig. 5b), but the mass loss of Control scaffolds was significantly greater than that of other scaffolds at all time points. At week 6, Control scaffolds had degraded to near $80 \%$. During incubation, it was also noticeable that Control scaffolds became more opaque, softer and stickier during 

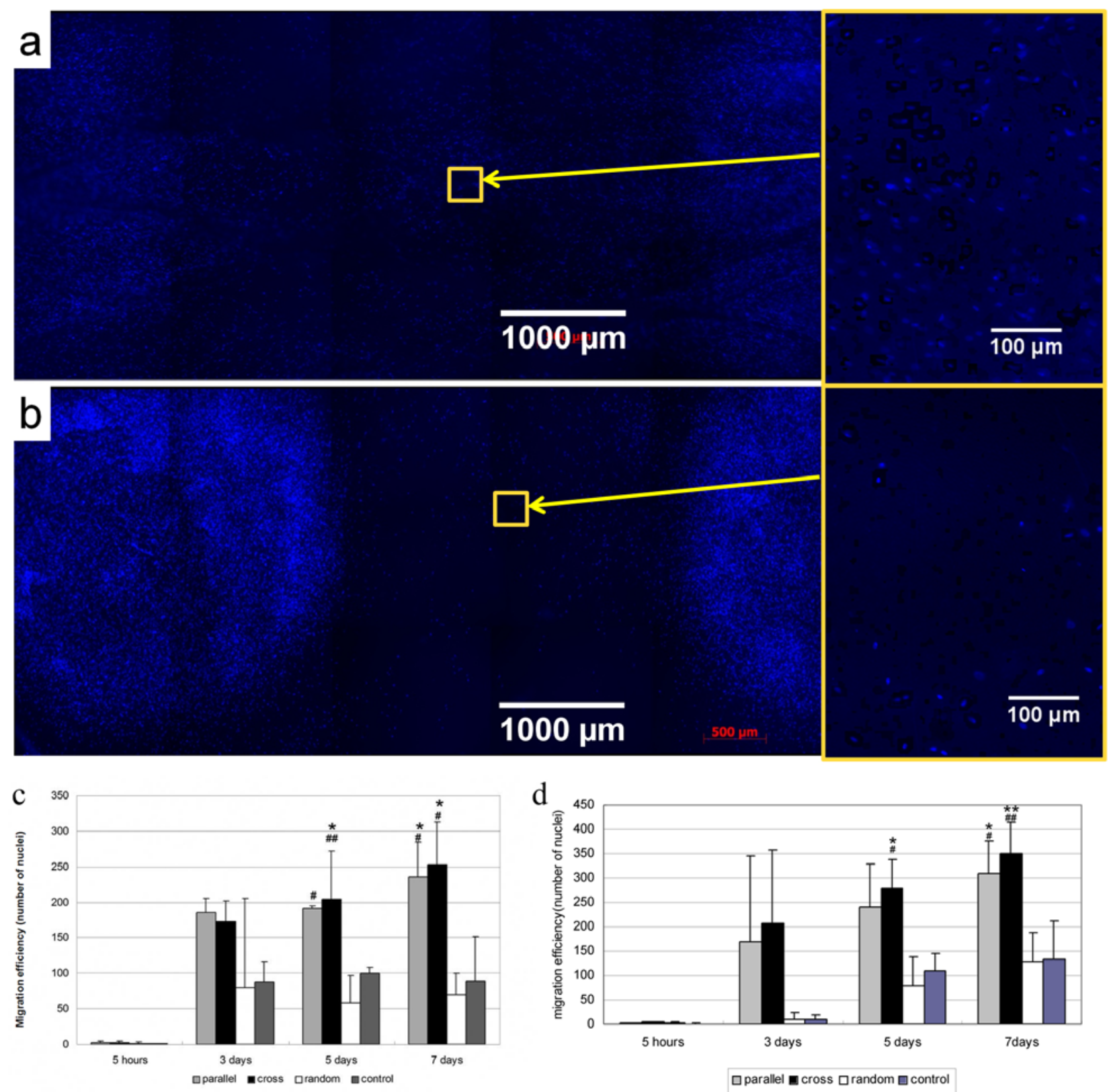

Fig. 9. Cell migration on Cross (a) and Random (b) scaffolds at day 3. Cell nuclei are stained blue. The migration efficiency was quantified by counting the number of cell nuclei in the middle area from the first (c) and second (d) run. Bars represent standard deviation (SD). * means $p<0.05$ compared to Control; ${ }^{*}$ means $p<0.05$, ${ }^{\#}<0.01$ compared to Random.

week 3. During week 4, mass loss of the Control scaffolds occurred to a larger extent and they became also fragile after freeze-drying.

\section{Behaviour of PDL cells on scaffolds}

Cell morphology. Fig. 6 and 7 show CLSM and SEM micrographs of the PDL cells on different PLGA scaffolds. Contact guidance of scaffolds was evident on aligned scaffolds. The PDL cells extended and aligned to a spindlelike shape (Fig. 7a). On the contrary, cells on Random scaffolds had a polygonal shape stretching across multiple fibres (Fig. 7b). Cells on Control scaffolds spread without any preferential orientation (Fig. 7c).

Cell attachment, proliferation and migration. Cell attachment, proliferation and migration were tested in two separate runs.
The first-run results from the Alamar Blue assay are shown in Fig. 8a. The metabolic activity of the cells on all scaffolds increased over time. The metabolic activity of the cells on both types of aligned fibres was always significantly higher, compared to the Control and Random scaffolds, except at day 3 when only the metabolic activity of the cells on the Cross scaffolds was increased. No other significant differences were found between Parallel and Cross scaffolds. The results from the second run showed the similar trend (Fig. 8c).

The results of the PicoGreen assay from the first and second run are shown in Fig. $8 \mathrm{~b}$ and $8 \mathrm{~d}$. The DNA, indicative for the amount of cells on the scaffolds increased to different extent over time. The value for Random scaffolds was significantly higher than for the Control scaffolds at day 3 and 7 . The value as found on both types 
of aligned fibres was significantly higher compared to Control as well as Random scaffolds at day 3, 5, and 7. There were no significant differences between Parallel and Cross scaffolds $(p>0.05)$.

Fig. 9 show the fluorescence micrographs of PDL cells on Cross and Random scaffolds at day 3. On the Cross scaffold, the edges of the two cell populations were no longer distinguishable due to cell migration. In contrast, the shape of the seeded cell area was still clearly visible on the Random scaffold. In the middle area, more cells were present on the Cross scaffold compared to the Random counterpart. The migration efficiency, as counted by the number of cell nuclei in the middle area from both the first and second run, is shown in Fig. 9c and 9d, respectively. At 5 hours after seeding, no cells were detected in the middle area of the scaffolds. At day 3, cells had migrated from the original cells clumps into the middle area, but no difference between the groups was found. At day 5 and 7, the cell clumps on both aligned scaffolds had completely merged together. Thus, the number of nuclei counted in the central part of the scaffold were significantly higher on the aligned substrates, compared to the Random and Control scaffolds. No significant differences were found between Random and Control scaffolds, nor between Cross and Parallel scaffolds, at any time point $(p>0.05)$.

\section{Discussion}

The advances in electrospinning technology have made it feasible to prepare fibrous structures with controlled alignment. Two methods are available to achieve this: first, by controlling the flight of the electrospinning jet by manipulating the electric field; second, by using a dynamic collection device, e.g., parallel electrodes and a fast rotating mandrel (Teo and Ramakrishna, 2006). However, the materials collected in either of these methods can only reach a thickness of a few fibre layers. With increasing thickness, the fibres become disordered, because of residual charge accumulation on the deposited fibres, which interferes with the alignment of incoming fibres (Teo and Ramakrishna, 2006). While, such a thin fibrous structure can be used to study cell behaviour, it can never be used as an actual scaffold to provide support to cells. Recently, a simple method was developed to collect continuous aligned electrospun fibre bundles by first depositing the fibres on a liquid medium (Smit et al., 2005; Khil et al., 2005). Although the electrospun fibres in such a method are randomly deposited on the water surface, the fibre mesh will elongate and thus align as the mesh is drawn over the surface of the water. In the current study, this method was modified and controlled woven scaffolds were made, which were composed of the aligned fibre bundles. By varying the movement of the drawing mandrel, unidirectional or crossed fibrous scaffolds were prepared. The thickness of the scaffolds was controlled by electrospinning time. Theoretically, a scaffold with any thickness can be made using this method.

In this study the stability and biodegradation of the aligned scaffolds, as made with the above electrospinning method, were characterized. The degradation results indicate that electrospun PLGA fibres degrade much slower than a PLGA film, which is consistent with the literature (Bajgai et al., 2008). The faster degradation of PLGA film is due to the slow diffusion rate of large degraded products containing acid-ending groups, which induce an autocatalytic effect in the centre of the films. For electrospun scaffolds, the interconnected porous structure makes it easier for the degraded oligomers to diffuse out, which prevents such autocatalysis. It should be noted that the degradation test in this study was performed without cell culture. Under cell culture conditions, the cells might secret certain enzymes, which also facilitate PLGA degradation. A previous study (Dong et al., 2009) performed degradation tests on PLGA electrospun scaffolds in cell culture up to 100 days, and found that cell culture accelerated electrospun PLGA scaffold degradation to some extent.

Besides degradation, PLGA scaffolds also showed shape instability during incubation. Previous studies indicated that electrospun PLGA scaffolds shrunk over $80 \%$ during the first 3 days of incubation (Li et al., 2006; Zong et al., 2003). It was proposed that such shrinkage was caused by fibre shortening during incubation (Li et al., 2006). In our study, we heat-treated the scaffolds before incubation, and this minimized the shrinkage intensively. However, a slight amount of shrinkage could still be observed. Compared to other scaffolds, the Random samples presented substantial shrinkage. Possibly, the aligned fibre bundle structure is more stable than the random fibres. Physical stability for a certain period of time is an important prerequisite for scaffolds in tissue engineering, and insufficient properties in this respect will severely limit possible applications. Specifically, for periodontal tissue regeneration, rapid shrinkage or too fast degradation of scaffolds will reduce its presence in the periodontal space. The epithelial cells, migrating faster than PDL cells, will extend downwards along the root of the tooth and block the repopulation of PDL cells in the defect space. Consequently, the bone fill, tissue coverage and periodontal regeneration achieved will be limited.

In addition, scaffolds for tissue regeneration should be able to resist physiologically relevant loads. In the present study, aligned scaffolds exhibited higher tensile stresses and Young's moduli, because fibre density in the direction of the loading force is a primary factor to determine the mechanical response. This result was similar to that of $\mathrm{Li}$ and co-workers (Li et al., 2006). The increased fibre alignment caused more force resistance along the loading direction. During the experiment, however, it was found that the Parallel scaffolds easily tore perpendicular to the fibre direction. The Cross scaffolds of course had resisting fibres distributed in different directions, thus were difficult to tear, and therefore will be easier to manipulate in a clinical situation. Also, the Young's modulus of the Cross scaffolds approached the mean value of cancellous bone, i.e., $493 \mathrm{MPa}$ (Petrie and Williams, 2007), and was much higher than human periodontal ligament, i.e. $0.11-0.96$ MPa (Yoshida et al., 2001). The measured Young's modulus suggests that our Cross scaffolds, when used for 
periodontal tissue regeneration, will be comparable to the natural cancellous bone tissues around the root, and will be strong enough to maintain the periodontal tissue regenerative space under the pressure from the gingival tissues and the chewing forces.

At the same time, it was observed that fibre alignment also influenced cell orientation. In the study of Hwang and co-workers (Hwang et al., 2009), it was shown that fibroblasts revealed a characteristic alignment on microscale fibres and that such an aligned cell orientation in turn guides the formation of an aligned fibrous extracellular matrix (Glass-Brudzinski et al., 2002; Wang et al., 2005). This phenomenon will be helpful to solve the common problem for current regenerative methods that only disorganized fibres can be formed.

Finally, our results showed that aligned fibres promoted directed cell movement. In contrast, the random oriented fibres hampered the migrational behaviour of the cells. As a consequence, the surface coverage of the PDL cells on the Random scaffolds was reduced compared to the Control scaffolds. This result was similar to the research of Johnson and co-workers (Johnson et al., 2009), in which it was revealed that glioma cells on aligned fibres migrated at a more effective velocity compared to those on random fibres. Evidently, aligned fibres can guide cell invasion and provide the "highways" for cell migration. The key factor to achieve periodontal tissue regeneration is fast migration and proliferation of PDL cells into the periodontal defect space. This makes it likely that aligned scaffolds can benefit periodontal tissue regeneration.

\section{Conclusions}

In this study, an improved electrospinning fabrication method with a grounded water bath was developed to prepare aligned fibrous scaffolds of approximately $200 \mu \mathrm{m}$ in thickness. The fibre alignment affected the mechanical properties and improved the structural stability of the scaffolds. In the cell culture experiment, aligned scaffolds directed the orientation of PDL cells and at the same time, enhanced the proliferation and migration of PDL cells. These results suggest that aligned electrospun fibres can be a good candidate scaffold material for periodontal tissue regeneration approaches. The clinical validity, however, needs to be investigated in vivo.

\section{Acknowledgments}

The authors would like to thank Dr. Sanne Both and Mr. Vincent Cuijpers for experimental assistance. This work was support by Natural Science Foundation of Hubei Province, China (2006AA412C09 and 2006ABA261), National Natural Science Foundation of China (30772445 and 30700948) and Royal Netherlands Academy of Arts and Sciences (KNAW, 08-PSA-M-02).

\section{References}

Ayres C, Bowlin GL, Henderson SC, Taylor L, Shultz J, Alexander J, Telemeco TA, Simpson DG (2006) Modulation of anisotropy in electrospun tissue-engineering scaffolds: Analysis of fiber alignment by the fast Fourier transform. Biomaterials 27: 5524-5534.

Bajgai MP, Kim KW, Parajuji DC, Yoo YC, Kim WD, Khil MS, Kim HY (2008) In vitro hydrolytic degradation of poly(e-caprolactone) grafted dextran fibers and films. Polym Degrad Stab 93: 2172.

Bartold PM, Xiao Y, Lyngstaadas SP, Paine ML, Snead ML (2006) Principles and applications of cell delivery systems for periodontal regeneration. Periodontol 41: 123135.

Chew SY, Mi R, Hoke A, Leong KW (2008) The effect of the alignment of electrospun fibrous scaffolds on Schwann cell maturation. Biomaterials 29: 653-661.

Chew SY, Wen Y, Dzenis Y, Leong KW (2006) The role of electrospinning in the emerging field of nanomedicine. Curr Pharm Des 12: 4751-4770.

Cortellini P, Tonetti MS (2000) Focus on intrabony defects: guided tissue regeneration. Periodontol 22: 104132.

Crea A, Dassatti L, Hoffmann O, Zafiropoulos GG, Deli G (2008) Treatment of intrabony defects using guided tissue regeneration or enamel matrix derivative: a 3-year prospective randomized clinical study. J Periodontol 79: 2281-2289.

Dong YX, Liao S, Ngiam M, Chan CK, Ramakrishna S (2009) Degradation behaviors of electrospun resorbable polyester nanofibers. Tissue Eng Part B-Reviews 15: 333351.

Dori F, Huszar T, Nikolidakis D, Tihanyi D, Horvath A, Arweiler NB, Gera I, Sculean A (2008) Effect of plateletrich plasma on the healing of intrabony defects treated with b-tricalcium phosphate and expanded polytetrafluoroethylene membranes. J Periodontol 79: 660669.

Edwards PC, Mason JM (2006) Gene-enhanced tissue engineering for dental hard tissue regeneration: (2) dentinpulp and periodontal regeneration. Head Face Med 2: 16.

Glass-Brudzinski J, Perizzolo D, Brunette DM (2002) Effects of substratum surface topography on the organization of cells and collagen fibers in collagen gel cultures. J Biomed Mater Res 61: 608-618.

Harrison RG (1912) The cultivation of tissues in extraneous media as a method of morphogenetic study. Anat Rec 6: 181-193.

Hwang CM, Park Y, Park JY, Lee K, Sun K, Khademhosseini A, Lee SH (2009) Controlled cellular orientation on PLGA microfibers with defined diameters. Biomed Microdevices 11: 739-746.

Johnson J, Nowicki MO, Lee CH, Chiocca EA, Viapiano MS, Lawler SE, Lannutti JJ (2009) Quantitative analysis of complex glioma cell migration on electrospun polycaprolactone using time-lapse microscopy. Tissue Eng Part C Methods 15: 531-540.

Khil MS, Bhattarai SR, Kim HY, Kim SZ, Lee KH (2005) Novel fabricated matrix via electrospinning for 
tissue engineering. J Biomed Mater Res Part B 72B: 117124.

Lee CH, Shin HJ, Cho IH, Kang YM, Kim IA, Park KD, Shin JW (2005) Nanofiber alignment and direction of mechanical strain affect the ECM production of human ACL fibroblast. Biomaterials 26: 1261-1270.

Li WJ, Cooper JA Jr, Mauck RL, Tuan RS (2006) Fabrication and characterization of six electrospun poly(ahydroxy ester) - based fibrous scaffolds for tissue engineering applications. Acta Biomater 2: 377-385.

Mailhot JM, Schuster GS, Garnick JJ, Hanes PJ, Lapp CA, Lewis JB (1995) Human periodontal ligament and gingival fibroblast response to TGF-b1 stimulation. J Clin Periodontol 22: 679-685.

Petrie CS, Williams JL (2007) Probabilistic analysis of peri-implant strain predictions as influenced by uncertainties in bone properties and occlusal forces. Clin Oral Implants Res 18: 611-619.

Pihlstrom BL, Michalowicz BS, Johnson NW (2005) Periodontal diseases. Lancet 366: 1809-1820.

Sanz M, Giovannoli JL (2000) Focus on furcation defects: guided tissue regeneration. Periodontol 2000 22: 169-189.

Smit E, Buttner U, Sanderson RD (2005) Continuous yarns from electrospun fibers. Polymer 46: 2419-2423.

Teo WE, Ramakrishna S (2006) A review on electrospinning design and nanofibre assemblies. Nanotechnology 17: R89-R106.

Wang HL, Greenwell H, Fiorellini J, Giannobile W, Offenbacher S, Salkin L, Townsend C, Sheridan P, Genco RJ (2005) Periodontal regeneration. J Periodontol 76: 1601-1622.

Weiss P (1934) In vitro experiments on the factors determining the course of the outgrowing nerve fiber. $\mathrm{J}$ Exp Zool 68: 393-448.

Xu CY, Inai R, Kotaki M, Ramakrishna S (2004) Aligned biodegradable nanotibrous structure: a potential scaffold for blood vessel engineering. Biomaterials 25: 877-886.

Yang F, Murugan R, Wang S, Ramakrishna S (2005) Electrospinning of nano/micro scale poly(L-lactic acid) aligned fibers and their potential in neural tissue engineering. Biomaterials 26: 2603-2610.

Yin Z, Chen X, Chen JL, Shen WL, Hieu Nguyen TM, Gao L, Ouyang HW (2010) The regulation of tendon stem cell differentiation by the alignment of nanofibers. Biomaterials 31: 2163-2175.

Yoshida N, Koga Y, Peng CL, Tanaka E, Kobayashi K (2001) In vivo measurement of the elastic modulus of the human periodontal ligament. Med Eng Phys 23: 567-572.

Zong X, Bien H, Chung CY, Yin L, Fang D, Hsiao BS, Chu B, Entcheva E (2005) Electrospun fine-textured scaffolds for heart tissue constructs. Biomaterials 26: 53305338.

\section{Discussion with Reviewers}

Reviewer I: The extracellular environment could impact the biodegradation rate and mechanical strength of a candidate scaffold for periodontal regeneration. How are these measures modified when the the scaffold is tested within the cell culture, rather than alone? Authors: In this study, we only examined the mechanical properties of the scaffolds at dry state to compare the effect of fiber alignment. In wet state, the mechanical strength of PLGA might be getting gradually lower due to the degradation of PLGA. Furthermore, under cell culture conditions, the cells may secrete enzymes, which can accelerate the degradation of PLGA, resulting in lowered mechanical properties. The effect of cell culture however is dependent on cell type. A previous study (Pan et al., 2008) indicated that in a co-culture of fibroblasts and macrophages, electrospun Dextran/PLGA scaffolds "showed faster degradation rate than their counterparts incubated with a single type of cells, as well as in PBS or cell culture medium". In contrast, another previous study (Dong et al., 2010) showed that "there was little difference in the loss of mechanical strength between (electrospun) PLGA degradation with and without (porcine smooth muscle) cell culture". In conclusion, the effect the presence of cells on the modulation of mechanical properties would require further systematic study.

Reviewer I: How do the autors envision the use of the scaffold for periodontal repair? Would the present scaffold allow vascularization of the TE construct (relatively low pore size and slow degradation)?

Authors: As mentioned in the Introduction, an organized scaffold architecture provides topographic cues to adherent cells, thus regulating the cell functions. It is known that PDL cells reside in a rather unique niche composed of oriented collagen fibres. Based on the tissue engineering concept, creating such a similar niche will help to regenerate $\mathrm{PDL}$ cell function. In this study, we demonstrated that the alignment of the scaffold fibres improved PDL cell attachment and proliferation and provided guidance cues on PDL morphology. We also hypothesize that the scaffold alignment influences PDL differentiation, which will be tested further.

Reviewer I: How could the design of the aligned electrospun scaffold be improved to allow tissue ingrowth and vascularization?

Authors: The present scaffold allows vascularization. One of our recent in vivo studies (unpublished data) showed that there were blood vessel in-growth for both random and aligned scaffolds when they were implanted subcutaneously in rats. It was also shown that the PLGA50:50 scaffolds were partially degraded after 6-week implantation. These results will be published separately.

Reviewer I: How are the mechanical properties of PLGA fibers comparable to the native periodontal ligament?

Authors: In tissue engineering, scaffolds play a vital role through preserving tissue volume, providing temporary mechanical function and/or delivering biomolecules. When considering periodontal tissue engineering, the successful scaffold should be able to maintain the periodontal tissue regeneration space under the pressure from the gingival 
tissues and the chewing forces. Unlike the native periodontal ligament, the scaffold fibers are not anchored in the tooth root covered with cementum, nor in the alveolar bone. Therefore, it is necessary that the scaffold fibers are much stronger than the native periodontal ligament in order to fulfill their mechanical function. In our study, the Young's modulus of the Cross scaffolds approached the mean value of cancellous bone and indeed were much higher than human periodontal ligament. Therefore, we think the mechanical properties of the PLGA fibers are adequate, for least at the beginning stages of the regenerative process. As PLGA is biodegradable, the scaffold may loose the mechanical strength after implantation. Ideally, the degradation rate of the scaffold should match the regeneration rate of periodontal ligament. We did not study the mechanical properties of the PLGA fibers during the degradation in this study, but it certainly should be a future point of attention.

Reviewer II: In my opinion, SEM image analysis may not the best way to measure scaffold size porosity. Did the authors tried other methods such as BET analysis or intrusion mercury porosimetry?

Authors: The purpose of the paper is to observe the effect of the surface topography of scaffolds on the seeded cells. By SEM image analysis, the pore size on the surface could be estimated. We did not try BET or intrusion mercury porosimetry for purely practical consideration. According to literature and our own experience, BET is only suitable for small pore sizes ranging from a few nanometers to 2 $\mu \mathrm{m}$ (Ho and Hutmacher, 2006) and intrusion mercury porosimetry is not suitable for compressible fragile scaffolds, such as electrospun scaffolds (Ho and Hutmacher, 2006; Pham et al., 2006).

Reviewer II: Aligned fibres promoted directed cell movement as reported already several time on the surface of the scaffold. It would have been very interesting to see what is the behaviour of the seeded cells in the whole 3D construct.

Authors: Although it has been reported that the aligned fibres promote cell movement, the innovative idea of this study is to demonstrate a new methods of fabricating aligned fibrous scaffold and prove that it has the positive effect on PDL cell proliferation and migration. We agree that the three dimensional features of our scaffold, e.g. the permeation of the seeded cells, is very important and interesting, therefore, it has been planned in our followingup study.

Reviewer III: Given that Fig. 2 shows (as I understand it) that there are two sets of aligned fibers at roughly $37^{\circ}$ orientation to each other for the "Cross films", it is difficult to understand that Fig. 4 shows that there is only one principal axis of the fibers for column B (cross). Please comment.

Authors: The fibre bundles are much bigger than the size of a PDL cell. Thus, at a high magnification, such as in Fig. 4, only one principal axis of the fibres can be observed.
Reviewer III: As shown in other of the Walboomers/ Jansen papers, the normal practice in demonstrating contact guidance of a substratum is either a plot of frequency of cells vs. their orientation or measurements of the $\%$ of cells having attached.

Authors: Walboomers worked on planar surfaces with regular texture enabling some deviation of the cell orientation, and thus such measurement has been done. Here, we did not quantify but only demonstrated the contact guidance effect. We did not give the plot of angle of cells vs. the principal axis of the fibre, as this would always coincide.

Reviewer III: The authors' conclusion "aligned microfibres....can be a good candidate scaffold material for periodontal tissue regeneration approaches' would be strengthened if it were to be demonstrated that the aligned microfibre substratum efficiently supported cell adhesion. Could the authors comment on the percentage of PDL cells that attach to the scaffold material and how that compares to other biomaterials, such as smooth PLGA films or Ti, and standard reference materials such as tissue culture plastic?

Authors: We agree that this is an interesting issue. The comparison in cell attachment between smooth and electrospun scaffolds can be found in our 5-hour attachment assay given in Fig. 8. In general, attachment to the fibers was equal to, or even surpassed the smooth PLGA. Of course, the enlarged available total surface area of a fibrous scaffold also plays a role in this. The comparison between PLGA and tissue culture plastic (TCP) was not included initially as TCP cannot be used as an implantable material. We have performed an additional 5-hour attachment assay, measuring total DNA, as described in this paper. Comparing the initially seeded cell aliquots with smooth TCP or PLGA, both materials had an attachment efficacy of $67 \pm 29 \%$ and $69 \pm 19 \%$, respectively, not resulting in a statistically significant difference.

\section{Additional References}

Dong YX, Yong T, Liao S, Chan CK, Stevens MM, Ramakrishna S (2010) Distinctive degradation behaviors of electrospun polyglycolide, poly(DL-lactide-coglycolide), and poly(L-lactide-co-e-caprolactone) nanofibers cultured with/without porcine smooth muscle cells. Tissue Eng Part A 16: 283-298.

Ho ST, Hutmacher DW (2006) A comparison of micro $\mathrm{CT}$ with other techniques used in the characterization of scaffolds. Biomaterials 27: 1362-1376.

Pan H, Jiang H, Chen W (2008) The biodegradability of electrospun Dextran/PLGA scaffold in a fibroblast/ macrophage co-culture. Biomaterials 29: 1583-1592.

Pham QP, Sharma U, Mikos AG (2006) Electrospun poly(epsilon-caprolactone) microfiber and multilayer nanofiber/microfiber scaffolds: Characterization of scaffolds and measurement of cellular infiltration. Biomacromolecules 7: 2796-2805. 